\title{
Imaging characteristics of mature cystic teratoma
}

\section{KEYWORDS: computed tomography, mature cystic teratoma}

Mature cystic teratoma is one of the most common, slow growing ovarian neoplasm found in a wide range of patient population. They are usually composed of elements two out of three germ cell layers like ectoderm, endoderm or mesoderm. It can be detected by ultrasound or CT scan with characteristic imaging findings. Presence of abundant fat, calcification or dentals components are often seen. Large lesions tend to have malignant potential (FIGURES 1 and 2).

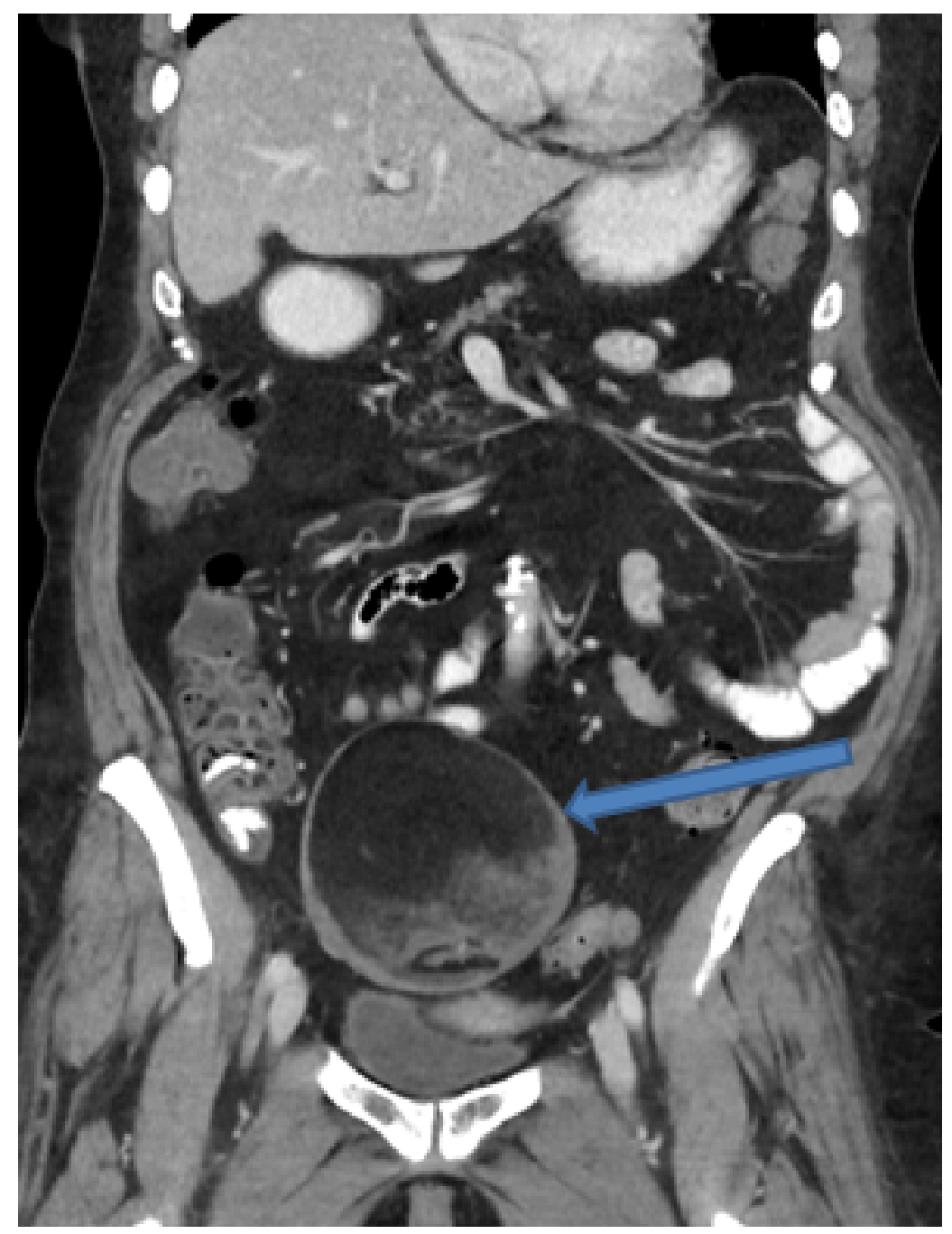

Figure 1. CT Abdomen and pelvis demonstrates a well defined large mass with internal fatty components (hypodense area denoted by arrow) arising from the right ovary consistent with mature cystic teratoma given large fatty components. 


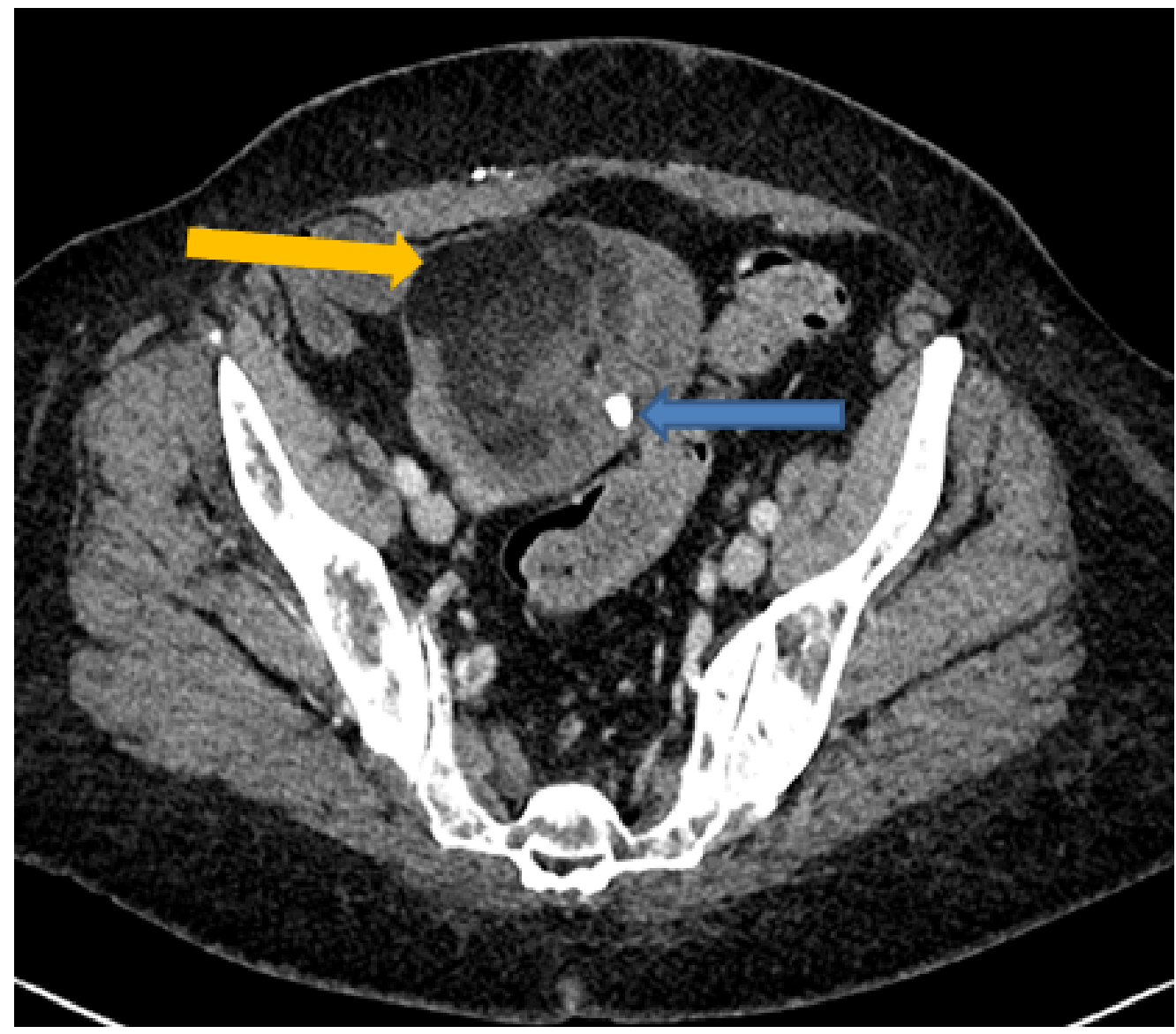

Figure 2. CT scan shows large mass with fatty components (arrow) and calcification (arrow) consistent with mature cystic teratoma. 